\title{
The impact of the COVID-19 pandemic on digital globalization
}

\author{
Maria Loredana Popescu ${ }^{1}$, Svetlana Platagea Gombos ${ }^{2}$, Sorin Burlacu ${ }^{1, *}$, and Amza Mair ${ }^{3}$ \\ ${ }^{1} \mathrm{PhD}$ Lecturer, Bucharest University of Economic Studies, Romania \\ ${ }^{2} \mathrm{PhD}$ Student, Bucharest University of Economic Studies, Romania \\ ${ }^{3} \mathrm{PhD}$ Student, Valahia University of Targoviste, Romania
}

\begin{abstract}
Research background: After more than a year of the Covid-19 pandemic, we can investigate whether it caused a shock to the global economy, pushing for deglobalization, or on the contrary, it was a challenge for digital globalization and digital transformation of economies. Through this research we join the research contributions that examine the process towards digital globalization that characterizes the world economy, its impact on businesses, consumers, and governments. We also discuss the challenges posed by the crisis caused by the coronavirus pandemic to globalization and perhaps the acceleration of the digital transformation of economies.

Purpose of the article: The aim of this research is to highlight the impact of the COVID-19 pandemic in the age of digital globalization.

Methods: Documentary analysis, as the main research method, is doubled by a case study that allows us to highlight the specific characteristics of digital globalization.

Findings \& Value added: The findings of the research allowed us to highlight the essential aspects of digital globalization that were perhaps exacerbated by the Covid-19 pandemic, but which contribute greatly to understanding the phenomenon of globalization. Our research also reveals four lessons learned in the COVID-19 pandemic. We also present some considerations regarding the globalization after the health crisis.
\end{abstract}

Keywords: digitization; globalization; COVID-19 pandemic

JEL Classification: $F 01 ; F 12 ; F 15$

\footnotetext{
* Corresponding author: sburlacu@amp.ase.ro
} 


\section{Introduction}

We subscribe to the idea that today more than ever, countries cannot be isolated from the global economy and globalization describes the growing interdependence of the world's economies, cultures and populations. The proliferation of digital platforms, accentuated by the COVID-10 pandemic, has generated an increase in data and information related to digital globalization and determines global economic, financial and social connections. More and more researchers believe that the Covid-19 pandemic has caused a shock to the global economy, perhaps faster and more severe than the global financial crisis of 2008, a shock that would push towards deglobalization. However, the conditionalities imposed by the authorities to eradicate the health crisis represent a challenge for digital globalization and the digital transformation of the economy (Schilirò, 2020).

Recent research considers that the functioning of the global economy in the COVID-19 pandemic makes it unlikely to return to the previous wave of globalization. They suggest that there would be an opportunity to address some of the weaknesses of globalization through a more regional global economy that would provide a better balance between national and international interests (Verma and Prakash, 2020).

The idea is also supported by a group of scientists in the fields of health, economics and labor relations who claim that COVID-19 is an unprecedented humanitarian crisis from which it cannot return to the "old normal". They believe that the disastrous global health impact of the pandemic has been exacerbated, which has exacerbated the unsustainability of economic globalization through major and simultaneous supply and demand disruptions. Neoliberal labor market regulation regimes have led to increases in inequality and precariousness at the national level (van Barneveld et al., 2020).

Song and Zhou's view that the COVID-19 pandemic broke out at a time when there were growing uncertainties in the global economy is noteworthy. They argue that understanding these uncertainties could provide an important background for analysing the impact of the pandemic on the global economy and assessing the effectiveness of policy measures to combat the pandemic and revitalize the global economy and predict the trajectory of the post-pandemic economic recovery. They thus identified three key factors that could lead to a solid recovery in the post-pandemic era: structural reform, new technology and reintegration. To manage the situation, he recommends the establishment of a new "global social contract" (Song and Zhou, 2020).

Wang and Sun believe that the Covid-19 pandemic has intensified the debate between optimists, pessimists and centrists about whether the world economic order is undergoing a fundamental change, noting that optimists predict continued economic globalization after the pandemic and pessimists expect localization instead of globalization (Wang and Sun, 2021).

\section{Methodology and results}

\subsection{Prospects for globalization}

We partially agree with Rashid's view in his brief A Perspective on Globalization (2021) that the future of work would be one of the most difficult challenges facing many researchers and managers around the world. Of course, the labor market is changing in digital globalization and current trends in robotics and artificial intelligence. Probably due to accelerated technology, many companies are ready to adopt digital solutions, stationary robots and drones, with consequences for declining jobs. His vision of providing a jobless society in which many roles will become automated minimizes the human role in these 
processes. It relies on the exacerbation of current trends and technological advances in which the impact of artificial intelligence on the future of work will be significant. In his paper he sought an analysis and clarification of the issues involved in terms of intelligent digitization, cognitive automation, the human-machine frontier and changing job types. He believes that the trend shows an increase in automation and computerization, and that in the future many craft jobs will be lost to office automation, arguing that the reasons behind this could be: increased productivity, reduced costs due to innovation and accelerating change (Rashid, 2021).

An eye-catching perspective on digital globalization is that of Ukrainian researchers who suspect that organizations are pragmatically approaching new technologies and focusing on what is no longer possible to do business without rushing to invest in fundamentally new fields. They considered that rapid and at the same time accurate changes in the regulatory framework would obviously be needed and it would be important to understand which aspects of them do not sufficiently correspond to the digital challenge and which are simply absent. It notes that a significant number of organizations believe that they could be encouraged to make more use of digital technologies, receiving government support and a quality regulatory environment that could have improved the well-being of society. They point out, however, that the impact of such a regulatory environment can be both negative and positive, which would not always be obvious. He argues this by the example of the behavior of entrepreneurs and individuals that would be largely due to changes in the regulatory framework, but that these changes would often be insignificant and difficult to predict or assess (Bogachov et al., 2021).

Perhaps one of the most worrying prospects for globalization is the one presented by a team of Chinese researchers investigating the degree and duration of the effects of misleading signaling on globalized digital platforms. They stated that sponsored listing would have emerged as a powerful tool for facilitating Internet-mediated exchanges in internationalization activities. Thus, some digital platforms based in poorly regulated countries offered sponsored lists to exporters without explicitly disclosing this sponsorship. This would be a misleading signal for importers in heavily regulated countries whose governments require disclosure of sponsorship. Their study investigates institutional hypnosis manifested in increasingly widespread and uncontrolled forms in digitized international business transactions. By uncovering and reporting a dark side of institutional arbitrage, they seek to provide practical implications for the governance of the digital platform, participants and regulators (Deng et al., 2021).

\subsection{Digital globalization}

Luo, in his recent research, believes that digitalization and globalization have converged to create a "new normal" of digital globalization. This has strengthened deeper, wider and more complicated connections between nations, companies and individuals. In fact, Luo reports that connectivity has redefined who participates in globalization and how international expansion takes place. However, this new reality would raise a number of complex issues that challenge existing international business theories and conclusions. We agree with Luo Luo's conclusions that globalization looks very different today due in large part to digitalization which has significantly changed the way we do business globally. However, Lou warns that global digital connectivity involves new types of risks that he believes would be underestimated. Moreover, the researcher's belief is that risk management would be one of the main objectives for companies operating internationally, and yet the international business exchange would have focused only on political risk, financial risk and transactional risk, leaving the risks largely unaddressed connectivity issues, both theoretically and empirically. The researcher believes that the risks would 
range from over-dependence to cyber-attacks, and those who want to understand the risks of connectivity should define and delineate them in detail. To develop new perspectives on managing growing interdependence amid connectivity, Lou recommends that researchers deepen a range of management issues, such as managerial control over critical joint activities and the global supply chain. Digital connectivity would lead companies to constantly innovate, to be structurally agile, and to become more and more network-based organizations (Luo, 2021).

The discussion about digital globalization would be incomplete without considering the digitalization of public administrations. Some Russian researchers believe that today the modern system of public administration is moving to digital public administration, to the creation of a national system for managing digital data, profiles and platforms. Their view is that the integration of digital transformation processes into the strategic system at the regional level will contribute to increasing the efficiency of state or regional management. This would be due to the increase in the speed of information exchange, which would build the potential for constant monitoring of socio-economic development and could make operational decisions in a timely manner. Thus, the use of tools to support the information technology of the work process could reduce the level of dependence on the human factor. In essence, they believe that effective strategic management of a region's development in a digital economy would only be possible if there are developed platforms, institutional and infrastructure environments and technologies. In their opinion, the blockchain is a promising technology that can be used in the field of strategic management of the development of the region. Government involvement in the development and implementation of blockchain technology could ultimately help reduce government complexity and costs. Among the main threats to the development of the regional digital economy in general and in the financial and budgetary sector in particular, Russian researchers believe, a significant place would be occupied by the lack of qualified staff, which is accompanied by a "brain drain" outside the region. of the country as a whole. A complete development of the information technology industry would be facilitated by measures that can support individual enterprises, research centers, educational institutions, etc. They stipulate that the emergence of large research centers would allow the region to become a leader in the scientific and technical process and ensure the implementation of state programs in the field of information technology and an innovative environment. In this way, human capital can be built to work in these centers and which would provide an investment flow both in the ICT sector itself and in the related sectors of the economy (Prikhodchenko et al., 2021).

\subsection{Lessons learned in the Covid-19 pandemic}

Empirical research during the Covid-19 crisis reports some lessons that could be learned from this experience and that humanity should learn from. A first lesson would be that international cooperation breaks easily during a crisis and that, without global cooperation, the costs for poorer or less able countries can be very high. A second lesson would be that a global crisis easily disrupts international supply chains, which can lead to a reduction in the volume of trade. A third lesson would be that a large-scale reduction in economic activity is not able to reduce global warming by $1.5^{\circ} \mathrm{C}$, which may suggest the need for much deeper social change, coupled with an ecological transformation that will decouple economic activity from carbon emissions. A clear understanding of what such an economy might look like is needed. The fourth lesson shows us that there is a willingness to finance a green post-crisis stimulus. However, it is not clear whether it is possible to design the incentives in such a way as to reduce inequality, which, according to the secretaries, was not considered following the 2008 financial crisis. In the fifth lesson we learn that the timing 
and preparation of political interventions can be decisive. This is exemplified by the fact that some countries that started the relatively late lockdown (e.g., Italy, the United Kingdom) recorded more casualties than other countries that were prepared for a potential pandemic (e.g., Taiwan). It is recommended that more attention be paid to the possible costs of delays, such as in the case of climate action, and a better understanding of how it is possible to promote international interests in national decision-making. Perhaps one last lesson is given by lockdowns around the world that they have shown that uncertainty can be a big problem for policy makers. Providing information is a key and decisive learning. Due to misinformation, false news or truncated information, lobbying, on the other hand, can become a serious problem as long as there is a dominant lobby group that mainly pursues its own interests. And perhaps the most important lesson learned in the Covid-19 pandemic, considered by these researchers, is that a crisis offers society the opportunity to promote a green transition faster than could have happened under normal conditions. One explanation could be given by the temporary undermining of interests that reduce pollution and mitigate climate change (Elliott et al., 2020).

\subsection{Globalization after COVID-19}

Mendoza and colleagues (2021) believe that globalization has been disrupted by the COVID-19 pandemic and that it may have raised additional economic, political and health challenges for many countries. This would increase the possibility of varying degrees of progress in establishing favourable institutional frameworks for full employment in the Fourth Industrial Revolution. They estimate that regionalism will grow at the expense of current multilateralism and may become even stronger in the post-COVID-19 world, a trend that could exacerbate inequality in several ways. We subscribe to their idea that technological revolutions contribute to stimulating globalization, but they also tend to go beyond the ability of governments to manage their implications. The consequences of this trend may be exacerbating inequality due to job losses for less skilled workers and increasing the large digital divide between populations with access to computers and the Internet and disadvantaged members of society without access, who are already relatively isolated due to the COVID-19 pandemic (Mendoza et al., 2021).

\section{Discussion and conclusions}

As expected, the impact of the COVID-19 pandemic on globalization is significant (Radulescu et al., 2021). The measures taken by the authorities to eradicate the pandemic have been relatively similar worldwide and have included, among others, measures of social distance, telework and online schooling (Balu et al., 2021). The relative uniformity of the measures to stop the pandemic, as well as its management by each country is perhaps the best demonstration of the existence of digital globalization (Burlacu et al., 2021). However, a characterization of digital digitization from the perspective of its utility is difficult to do. If at first sight this brings undisputed benefits in terms of the speed of transmission of information needed to make decisions or substantiate them, perhaps this speed is accompanied by a number of shortcomings (Sarbu et al., 2021).. And we are not talking about technical errors but rather strategic shortcomings such as limiting creativity, perspective, innovation and risk. Future research is needed to understand the mechanism of digital globalization and its levers in the right directions of good governance. 


\section{References}

1. Balu, F. O., Radulescu, C. V., Bodislav, D. A., Gole, I., Buzoianu, O. C. A., Burlacu, S., \& Balu, P. E. (2021). Cost modeling and computation in the healthcare industry. Case study on a Swiss medical care organization. Economic Computation \& Economic Cybernetics Studies \& Research, 55(1).

2. Bogachov, S., Pluhatar, T., Plakhotnik, O., Alieksieieva, O., \& Bondar, V. (2021). Innovative business development in the digital economy. Entrepreneurship and Sustainability Issues, 8(4), 682-696.

3. Burlacu, S., Diaconu, A., Balu, E. P., \& Gole, I. (2021). The Economic and Social Effects of Unemployment in Romania. Revista de Management Comparat International, 22(1), 21-27.

4. Burlacu, S., Patarlageanu, S. R., Diaconu, A., \& Ciobanu, G. (2021). E-government in the era of globalization and the health crisis caused by the covid-19 pandemic, between standards and innovation. Les Ulis: EDP Sciences.

5. Deng, Z., Liesch, P. W., \& Wang, Z. (2021). Deceptive signaling on globalized digital platforms: Institutional hypnosis and firm internationalization. Journal of International Business Studies, 52(6), 1096-1120.

6. Elliott, R. J. R., Schumacher, I., \& Withagen, C. (2020). Suggestions for a Covid-19 Post-Pandemic Research Agenda in Environmental Economics. Environmental and Resource Economics, 76(4), 1187-1213.

7. Luo, Y. (2021). New OLI advantages in digital globalization. International Business Review, 30(2), 101797.

8. Mendoza, R., Balisacan, A., Valenzuela, S., David, C., \& Ducanes, G. (2021). Navigating Globalization in the Aftermath of COVID-19. ASOG WORKING PAPER 21-004.

9. Prikhodchenko, O., Panskov, V., \& Afanasyeva, L. (2021). Modern Trends in the Development of the Regional Economic Management System in the Context of Digital Globalization. SHS Web of Conferences, 92, 07053.

10. Radulescu, C.V., Ladaru, G.R., Burlacu, S., Constantin, F., Ioanăș, C., \& Petre, I.L. (2021). Impact of the COVID-19 Pandemic on the Romanian Labor Market. Sustainability, 271.

11. Rashid, M. (2021). A brief perspective on globalization. University of California Davis. University of Detroit Mercy, 108045.

12. Sarbu, R., Alpopi, C., Burlacu, S., \& Diaconu, S. (2021). Sustainable urban development in the context of globalization and the health crisis caused by the covid19 pandemic. Les Ulis: EDP Sciences.

13. Schilirò, D. (2020). Towards digital globalization and the covid-19 challenge. International Journal of Business Management and Economic Research, 2(11), 17101716.

14. Song, L., \& Zhou, Y. (2020). The COVID-19 Pandemic and Its Impact on the Global Economy: What Does It Take to Turn Crisis into Opportunity? China and World Economy, 28(4), 1-25.

15. van Barneveld, K., Quinlan, M., Kriesler, P., Junor, A., Baum, F., Chowdhury, A., Junankar, P. N., Clibborn, S., Flanagan, F., Wright, C. F., Friel, S., Halevi, J., \& Rainnie, A. (2020). The COVID-19 pandemic: Lessons on building more equal and sustainable societies. Economic and Labour Relations Review, 31(2), 133-157. 
16. Verma, A. K., \& Prakash, S. (2020). Rising regionalization: will the post-COVID-19 world see a retreat from globalization? Transnational Corporations Journal, 09(5), 7352-7363.

17. Wang, Z., \& Sun, Z. (2021). From Globalization to Regionalization: The United States, China, and the Post-Covid-19 World Economic Order. Journal of Chinese Political Science, 26(1), 69-87. 